\title{
LOS ENEMIGOS DE LA PATRIA. LA REPRESENTACIÓN DEL OTRO DURANTE LA GUERRA CIVIL ESPAÑOLA EN LOS TEXTOS ESCOLARES DEL FASCISMO ITALIANO $(1936-1943)^{\alpha}$
}

\author{
The enemies of the homeland. The representation of the other \\ during the Spanish Civil War in the textbooks of Italian Fascism
} (1936-1943)

\section{Carlos Sanz Simón ${ }^{\beta}$}

Fecha de recepción: 23/10/2019 • Fecha de aceptación: 13/01/2020

Resumen. La Guerra Civil Española (1936-1939) fue un campo de batalla que, si bien se desarrolló en el territorio nacional, tuvo un alcance y participación que traspasó las fronteras del país. El bando sublevado contó con la ayuda principal de dos potencias extranjeras para acabar con la Segunda República: la Alemania nazi y la Italia fascista. Sería precisamente esta última la que invirtiera un mayor esfuerzo económico y logístico, pues Mussolini vería en España un posible aliado mediterráneo, afín a su modelo del fascismo italiano. La presente investigación se propone conocer cuál fue la representación del enemigo, en este caso el bando republicano, en los textos escolares de los últimos años de la dictadura del Duce en Italia. Los textos han sido consultados en el Centro di documentazione e ricerca sulla storia del libro scolastico e della letteratura per l'infanza - Museo Paolo e Ornella Ricca de la Università degli Studi di Macerata (Italia). Los resultados muestran cómo los manuales escolares

\footnotetext{
${ }^{\alpha}$ El presente trabajo recibió el premio Herminio Barreiro a la mejor comunicación en la categoría de doctorandos/as en el XX Coloquio de Historia de la Educación - Congreso internacional «Identidades, internacionalismo, pacifismo y educación», celebrado en Monforte de Lemos - Ourense entre el 9 y 12 de julio de 2019 por la Sociedad Española de Historia de la Educación. Asimismo, esta investigación se ha llevado a cabo gracias a la concesión de un contrato predoctoral de personal investigador en formación de la Universidad Complutense de Madrid cofinanciado por el Banco Santander (CT17/17-CT18/17).

${ }^{\text {B }}$ Departamento de Estudios Educativos. Universidad Complutense de Madrid. C/Rector Royo Villanova s/n, 28040 Madrid. España. csa02@ucm.es (ID https://orcid.org/0000-0002-5786-4024
}

Cómo citar este artículo: Sanz Simón, Carlos. «Los enemigos de la Patria. La representación del otro durante la Guerra Civil Española en los textos escolares del fascismo italiano (1936-1943)». Historia y Memoria de la Educación 12 (2020): 333-360 
de la época, de materias como historia, lecturas, geografía o enseñanzas patrióticas, reflejaban una imagen del bando republicano asociada a la tiranía, demonizando su intervención en el conflicto bélico con narraciones que exaltan la violencia, el anticatolicismo y la vinculación con el comunismo soviético o la anarquía.

Palabras clave: Guerra civil española; Fascismo italiano; Alteridad; Enemigo; Manuales escolares.

Abstract. The Spanish Civil War (1936-1939) was a battlefield that, although it developed nationally, had a scope and participation that crossed the borders of Spain. The rebel side asked for help of two foreign powers in challenging the Second Republic: Nazi Germany and Fascist Italy. It would be precisely the latter that would invest a greater economic and logistical effort, due to how Mussolini saw in Spain a possible Mediterranean ally, one akin to his model of Italian fascism. The present research attempts to discover how the enemy - in this case the Republican side - was represented in the school textbooks of the last years of the Duce's dictatorship in Italy. The texts were consulted in the Centro di documentazione e ricerca sulla storia del libro scolastico e della letteratura per l'infanza at the University of Macerata (Italy). The results show how the school manuals of that time, in subjects such as history, readings, geography or patriotic teachings, reflected an image of the republican side associated with tyran$n y$, demonizing their intervention in the warlike conflict with narratives that exalt violence and anti-Catholicism and identifying them with Soviet communism and anarchy.

Keywords: Spanish Civil War; Italian fascism; Alterity; Enemy; Textbooks.

\section{INTRODUCCIÓN}

Los conflictos bélicos acaecidos en la Europa de la primera mitad del siglo XX supusieron acontecimientos fundamentalmente identitarios. La reafirmación de la concepción de ser, seguido de una nacionalidad determinada, trajo consigo una cadena de guerras que asolaron al viejo continente.

No obstante, podemos distinguir en este contexto histórico dos tipos de guerra en función de su marco político y/o geográfico. La primera comprende a aquellas que se dieron entre bloques de países que defendían unos ideales determinados en un espacio comprendido por distintos estados, como las guerras mundiales; y la segunda a las que se daban en un campo de batalla únicamente nacional —aunque existiera una 
presencia y participación internacional-, como el caso de la Guerra Civil Española (1936-1939). ${ }^{1}$

Este conflicto, ampliamente estudiado en la historiografía nacional e internacional, ha ocupado asimismo un importante espacio en el ámbito histórico-educativo. ${ }^{2}$ En este campo, el presente trabajo se centra en el caso concreto de la intervención italiana en la Guerra Civil y la representación del enemigo común: el bando republicano. ${ }^{3}$

\title{
La implicación de Mussolini en la contienda tuvo importantes ante- cedentes en el contexto directo español. Durante la dictadura de Primo
}

\begin{abstract}
${ }^{1}$ La Guerra Civil española fue un conflicto bélico que se inició el 17 de julio de 1936 y finalizó el 1 de abril de 1939. Tuvo lugar tras el levantamiento del bando sublevado - encabezado por el general Francisco Franco- contra el régimen democrático de la Segunda República (1931-1936). La contienda dejó medio millón de muertes según las estimaciones aproximadas más generalizadas, y finalizó con la victoria de los sublevados, teniendo como resultado la implantación de la dictadura franquista (1939-1975).
\end{abstract}

2 Sirvan de ejemplo algunos trabajos sobre esta temática analizando el conflicto bélico español en textos escolares de distintas épocas: Emilio Castillejo Cambra, Mito, legitimación y violencia simbólica en los manuales escolares de Historia del franquismo (Madrid: UNED, 2008); Juan Carlos Colomer Rubio, "La Guerra Civil y el Franquismo en libros de texto actuales de $6 .^{\circ}$ de primaria: una aproximación crítica», en Pensar con la historia desde el siglo XXI: actas del XII Congreso de la Asociación de Historia Contemporánea, coords. Pilar Folguera et al. (Madrid: Universidad Autónoma de Madrid, 2015), 5175-5185; Juan Carlos Bel Martínez y Juan Carlos Colomer Rubio, «Guerra Civil y franquismo en los libros de texto actuales de Educación Primaria: análisis de contenido y orientación didáctica en el marco de la LOMCE», Cabás 17 (2017): 1-17; Christian Roith, "Representaciones de la Guerra civil española en manuales de Historia del franquismo temprano", Historia de la Educación. Revista interuniversitaria 36 (2017): 321-342; Rafael Valls Montes, Historia y memoria escolar: Segunda República, Guerra Civil y dictadura franquista en las aulas (1938-2008) (València: Universitat de València, 2009).

${ }^{3}$ Los estudios en el ámbito de la Historia de la Educación entre España e Italia fueron una línea de investigación sugerida en el I Workshop Italo-Español de Historia de la Cultura Escolar, celebrado en Berlanga de Duero en noviembre de 2011. Asimismo, en España recientemente han aparecido estudios sobre el caso concreto de Italia. Asimismo, véanse los siguientes trabajos: Francisco Morente Valero, «Los fascismos europeos y la política educativa del franquismo», Historia de la Educación. Revista interuniversitaria 24 (2005): 179-204; Juri Meda y Ana $\mathrm{M}^{\mathrm{a}}$ Badanelli Rubio, La historia de la cultura escolar en Italia y en España: Balance y perspectivas (Macerata: Edizioni dell'Università di Macerata, 2013); Rubén Domínguez Méndez, «La fascistización de las escuelas italianas en el extranjero. El caso de Barcelona (1922-1929)», Historia de la Educación. Revista interuniversitaria 33 (2014): 231-253; Luigiaurelio Pomante y Roberto Sani, «The Gentile reform (1923) and academic strategies of the University of Macerata between national science and development of the local economy», Historia y Memoria de la Educación 3 (2016): 259-277; Luca Montecchi, «La escuela primaria rural en Italia entre los siglos XIX y XX», Historia y Memoria de la Educación 7 (2018): 81-106; Juri Meda, «'Invisible schools'. The public image of rural schools in Southern Italy in photographic inquiries and photo-reportages (1925-55)», Historia y Memoria de la Educación 8 (2018): 347-396; María Cristina Morandini, «I quaderni di epoca fascista veicolo di propaganda ideologica e strumento didattico: il fondo della scuola elementare Parini di Torino (1938-1942)», Historia y Memoria de la Educación 10 (2019): 383-408. 
de Rivera, este se mostró como un claro admirador del Duce, si bien declaró que no era su objetivo crear un Estado fascista al estilo del italiano. Tampoco Mussolini consideró a finales de los años veinte que el fascismo fuera un sistema exportable. ${ }^{4}$ Con el advenimiento de la Segunda República, el dictador italiano adoptó una postura hostil con el sistema democrático español, llegando incluso a intentar acabar con él desde su proclamación. ${ }^{5}$ Tres fueron los grandes intentos de la dictadura fascista para dar fin al régimen democrático de 1931. El primero, en 1932, cuando facilitó armas para el golpe del general Sanjurjo. El segundo, en 1934, dando municiones y armas a los monárquicos, alfonsinos y carlistas, y promoviendo una alianza entre los partidos de la derecha española filofascista, que, si bien en Italia se reunían en torno a un bloque compacto, en España este estaba claramente fragmentado. Y, por último, en 1935, con la financiación de la Falange de José Antonio Primo de Rivera. ${ }^{6}$

Sin embargo, la intervención definitiva y directa del fascismo italiano para terminar con el proyecto de la Segunda República llegó con la Guerra Civil Española. Cuando el bando sublevado se levanta, Franco solicita ayuda a las fuerzas fascistas extranjeras, en especial a la Italia de Mussolini. Como señala Ángel Viñas, Franco «no hizo nada similar con Hitler, quizá porque el Tercer Reich le caía, en aquellos momentos, un tanto lejano y se sentía más cómodo con el vecino latino». ${ }^{7}$

Mussolini, inicialmente, optó por no financiar el golpe pese a sus intentos de acabar con el sistema democrático español unificando a la derecha próxima al fascismo, y a financiar directamente a la Falange de José Antonio. ${ }^{8}$ Las hipótesis sobre esta decisión se decantan por dos vías:

\footnotetext{
${ }^{4}$ Stanley George Payne, Fascism in Spain (1923-1977) (Madison: University of Wisconsin Press, 1999).

5 Julián Casanova Ruiz, República y guerra civil. Volumen 8 (Barcelona: Crítica - Marcial Pons, 2007).

- Ismael Saz Campos, Mussolini contra la II República. Hostilidad, conspiraciones, intervención (1931-1936) (Valencia: Alfons el Magnànim, 1986); Claudio Venza, «La Italia fascista en la tormenta española (1934-1939)», en Francone. La mirada de Mussolini en la guerra de España, ed. Gobierno de Aragón (Zaragoza: Gobierno de Aragón, 2009), 31-40.

7 Ángel Viñas, La República en guerra contra Franco, Hitler, Mussolini y la hostilidad británica (Barcelona: Crítica, 2012), 104.

${ }^{8}$ Ismael Saz Campos, Mussolini contra la II República.
} 
en primer lugar, que en un principio no vio claras las opciones de éxito del bando sublevado, y, en segundo lugar, por el reciente éxito de Italia en Etiopía, no viendo la necesidad de entrar en otro conflicto bélico que pudiera cuestionar las posibilidades militares del fascismo..$^{9}$ No obstante, la decisión definitiva de la participación italiana vendría de la mano de los informes del Servizio informazioni militare (Servicio de información militar), que finalmente mostraban la conveniencia y las opciones de éxito de involucrarse en la guerra española. La finalidad inicial de su participación, como apunta Ismael Saz, fue de carácter ideológico e imperialista o de potencia. ${ }^{10}$ En este sentido, y como completa Morten Heiberg, si bien la hipótesis de la finalidad es discutida, no parece atrevido afirmar que Mussolini vería en la entonces futurible España de Franco un posible aliado o Estado satélite mediterráneo, incrementando así su influencia en el continente europeo en detrimento del eje franco-británico. ${ }^{11}$ Todo ello a pocos años del estallido de la Segunda Guerra Mundial.

El mapa de la participación italiana puede trazarse en tres ejes o frentes: la zona sur, donde destacó la rápida y exitosa batalla de Málaga para el ejército italiano, en febrero de 1937; la zona norte, donde tuvo lugar la batalla de Santander y la redención vasca, entre agosto y septiembre del mismo año; y la zona centro, escenario de la derrota fascista en la batalla de Guadalajara —en marzo de 1937- la cruenta batalla del Ebro y las actuaciones en los frentes del Levante y Cataluña. Asimismo, hay que destacar el papel crucial que tuvieron las islas Baleares para la aviación italiana, sirviendo como base militar. Por último, finalizada ya la guerra, los soldados italianos se dirigieron a Nápoles, donde fueron recibidos por el rey Víctor Manuel III y Gian Galeazzo Ciano, entonces ministro de Asuntos Exteriores. La ausencia de Mussolini se debió a la tensa relación que mantenía ya por entonces con el monarca, algo que no sentó bien en las filas de militares que volvieron de una guerra que se había cobrado 3.796 víctimas del ejército italiano. ${ }^{12}$

\footnotetext{
${ }^{9}$ Claudio Venza, «La Italia fascista en la tormenta española (1934-1939)».

${ }^{10}$ Ismael Saz Campos, Mussolini contra la II República.

${ }_{11}$ Morten Heiberg, Emperadores del Mediterráneo. Franco, Mussolini y la guerra civil española (Barcelona: Crítica, 2003).

12 Dimas Vaquero Peláez, Credere, obbedire, combattere. Creer, obedecer, combatir... y morir. Fascistas italianos en la guerra civil española (Zaragoza: Mira Editores, 2007); Dimas Vaquero Peláez, Mussolini \& España, Franco \& Mussolini. Unas relaciones difíciles (Zaragoza: Comuniter, 2017).
} 
Dado este contexto, la presente investigación se propone conocer cuál fue el grado de internacionalización de este fenómeno en la cultura escolar del fascismo italiano, analizando la presencia de este conflicto y la definición del otro o enemigo a batir en los textos escolares de enseñanza elemental o primaria de la dictadura fascista de Benito Mussolini.

\section{LA ALTERIDAD COMBATIDA. LA REPRESENTACIÓN DEL OTRO EN LA GUERRA CIVIL ESPAÑOLA}

Las guerras son una cuestión de identidad. Suponen un despliegue militar masivo y la reafirmación de un yo o nosotros. Pero también reafirma al otro en cuanto a un antagonismo excluyente de lo que implica la propia identidad. Como señala el historiador Xosé Manoel Núñez Seixas:

La confrontación entre dos colectivos supone la consagración definitiva de una imagen estereotipada de otro, que se convierte así en la contraimagen necesaria para consolidar una imagen propia del yo nacional, ex-novo o bien a partir de los rasgos previamente fijados por el proceso de construcción nacional desarrollado por instituciones, élites intelectuales y movimientos sociales. El otro puede ser aquél ya señalado por la narrativa nacional anterior, puede convertirse en un nuevo oponente, o puede ser incardinado en un continuum de amenazas exteriores (y, a veces, interiores), cuya sucesión prueba la capacidad de la patria para renovar su existencia mediante el sacrificio de sus hijos. En esa narrativa de la alteridad combatida, los viejos enemigos se convierten en nuevos, y los nuevos en viejos. ${ }^{13}$

De las palabras del autor se infiere que la construcción de la identidad del otro puede formar parte de una narrativa nacional ya establecida o surgir espontáneamente por circunstancias coyunturales, e incluso a través de amenazas internas, como es el caso de la Guerra Civil Española. Asimismo, resulta relevante señalar que la transmisión de este relato y de la identidad del otro o alteridad, implica la acción de diferentes actores sociales, pero fundamentalmente de la escuela. Por tanto, al transmitir la

\footnotetext{
13 Xosé Manoel Núñez Seixas, «El miedo al extranjero, o el enemigo como invasor (1936-1939)», en Retóricas del miedo: imágenes de la guerra civil española, eds. Nancy Berthier y Vicente Sánchez-Biosca (Madrid: Collection de la Casa de Velázquez, 2012), 53.
} 
idea de una identidad se proyecta, explícita o implícitamente, la identidad del otro.

Dentro de la Guerra Civil, entendida esta como un conflicto bélico de carácter doméstico, por ocurrir en el territorio de un solo estado, se produjo la lucha entre dos concepciones o identidades antagónicas en un mismo país. La España que se identificó con el bando sublevado, a las órdenes del general Francisco Franco, se revolvió contra el reformismo social y político de la Segunda República, el comunismo, el socialismo y las democracias occidentales. ${ }^{14}$ En términos de Francisco Sevillano, el bando sublevado, partiendo del extrañamiento y de la estigmatización del enemigo, declaró a los rojos como enemigos absolutos. ${ }^{15}$

Sin embargo, en esta concepción maniqueísta del conflicto bélico español no debemos caer en el simplismo de concebir estos dos bloques antagónicos como compactos y homogéneos. Como señaló la historiadora hispanista Carolyn Boyd, en el caso del bando franquista, existían múltiples familias en función de las clases sociales, metas e ideologías. Pero tenían un objetivo común: acabar con la España republicana e imponer el denominado nacionalcatolicismo, exaltando la comunión de un patriotismo exacerbado y arraigado en los referentes de los Reyes Católicos y la España imperial, por un lado, y la religión católica por otro. ${ }^{16}$

Los textos escolares del franquismo comenzaron su andadura recogiendo un modelo de marcado carácter conservador y castrense ya existente durante el periodo republicano. ${ }^{17}$ La política del libro escolar reflejó nueva y explícitamente las diferencias entre Falange e Iglesia, pues la primera buscaba la implantación del texto único, evocando a su antecesor, el dictador Miguel Primo de Rivera, y al referente italiano de Mussolini. En cambio, la Iglesia católica defendió la implantación de una comisión para su revisión, que limitara el contenido pero que le dejara cierto margen de autonomía, respondiendo así también a los intereses

\footnotetext{
${ }_{14}$ Morten Heiberg, Emperadores del Mediterráneo.

${ }^{15}$ Francisco Sevillano Calero, La cultura política del «nuevo Estado» franquista. Enemigos, héroes y caídos de España (Madrid: Biblioteca Nueva, 2017).

16 Carolyn P. Boyd, Historia patria. Política, historia e identidad nacional en España: 1875-1975 (Barcelona: Pomares Corredor, 2000).

${ }^{17}$ Carlos Sanz Simón y Teresa Rabazas Romero, «La identidad nacional en los manuales escolares durante la Segunda República Española», Bordón. Revista de Pedagogía 69, no. 2 (2017): 131-146.
} 
editoriales. Los textos, en consecuencia, se impregnaron del ideario nacionalcatólico, excluyendo a la otra España y con otra ruptura entre falangistas y católicos. Si bien ambos aludían a la época imperial como un periodo que servía de inspiración, los segundos lo hacían como si se tratara de un modelo político, social y espiritual válido y aplicable en el franquismo. ${ }^{18}$

Sin embargo, si bien el discurso del Régimen obviaba el pasado inmediato, no desaprovechó la oportunidad de deslegitimar a la Segunda República, mostrando una versión de este periodo alterada y peyorativa. En concreto, la representación del enemigo reflejó una concepción de los partidarios de la república como fuente de todos los males. ${ }^{19}$ Los textos dibujaban un pasado apocalíptico, criticando e insultando duramente al liberalismo, el socialismo y el republicanismo de 1873 y $1931 .{ }^{20}$ Las críticas fundamentales apuntaban a las luchas partidistas y al anticlericalismo, mientras de la Segunda República se aludía a «la quema de conventos, el desorden, el conflicto social, el separatismo y el "comunismo" ». ${ }^{21}$ Finalmente, del conflicto bélico civil, en esta primera fase se obviaron las razones que habían llevado a la guerra en los manuales escolares. ${ }^{22}$

Como se ha mostrado anteriormente, la literatura académica nos permite conocer cuál fue el revisionismo histórico llevado a cabo en los textos escolares por el franquismo en los años de la Guerra Civil Española e inmediatamente posteriores. El presente trabajo pretende conocer cuál fue la visión que dio la Italia fascista de la identidad del enemigo o alteridad combatida, en términos de Núñez Seixas, en el contexto de la Guerra Civil Española o Guerra di Spagna. La elección de este Régimen no es casual, pues como se ha señalado anteriormente, Franco

\footnotetext{
18 Carolyn P. Boyd, Historia patria.

19 Marcos Marina Carranza, «¿Qué guerra civil nos han explicado? La guerra civil en los libros de texto", en Historia, identidad y alteridad. Actas del III Congreso Interdisciplinar de Jóvenes Historiadores, coords. José Manuel Aldea Celada et al. (Salamanca: Hergar Ediciones, 2012), 715.
}

\footnotetext{
20 Entre 1873 y 1874 tuvo lugar en España la Primera República, un periodo breve pero políticamente inestable. Fue proclamada tras la abdicación del rey Amadeo I de Saboya (1871-1873), y finalizó con la restitución de la monarquía borbónica bajo el reinado de Alfonso XII (1874-1885), hijo de Isabel II (1833-1868).

21 Carolyn P. Boyd, Historia patria, 219.

22 Carolyn P. Boyd, Historia patria, 219.
} 
recurrió a su homólogo italiano con especial interés. Y es que Mussolini terminaría convirtiéndose en el mayor baluarte de la ayuda internacional del bando sublevado. En este sentido, como apunta Álvaro Lozano, la dictadura del Duce fue el principal aliado del bando sublevado, haciendo un esfuerzo superior al de Hitler, prácticamente desde la proclamación de la Segunda República. ${ }^{23}$

Todo ello incrementa el interés por saber cuál fue la representación y concepción que la educación italiana plasmó en sus textos escolares sobre la Guerra Civil Española, la intervención italiana en la misma y el enemigo común. Especialmente el caso de este último - y el que aquí nos concierne-, el cual se utilizó como una oportunidad de generar el rechazo en las nuevas generaciones instruidas en la escuela del fascismo italiano, pero también como una herramienta para la construcción y reafirmación de la propia identidad nacional.

\section{METODOLOGÍA}

La presente investigación sigue una metodología histórico-educativa, utilizando como fuentes primarias los libros de texto de la enseñanza elemental o primaria de la Italia fascista entre los años 1936 y 1943, desde el comienzo de la Guerra Civil a la caída de Benito Mussolini como presidente del consejo de ministros.

Como señaló Manuel de Puelles, «el nacionalismo considera la escuela como el instrumento por excelencia para la integración nacional y para la transmisión de valores y símbolos que constituyen ese sujeto, muchas veces hipostasiado, que es la comunidad nacional».24 En este sentido, el manual escolar se erige como una fuente crucial para la prescripción del currículum nacional y su estudio, ya que como indicó Alain Choppin, «más allá de las estrechas prescripciones de un programa, los manuales transmiten un sistema de valores, una ideología, una cultura». ${ }^{25}$ Además, los textos

\footnotetext{
${ }^{23}$ Julián Casanova Ruiz, República y guerra civil; Álvaro Lozano, Mussolini y el fascismo italiano (Madrid: Marcial Pons Historia, 2012).

24 Manuel de Puelles Benítez, Política, legislación y educación (Madrid: UNED, 2017), 47-48.

25 Alain Choppin, «Pasado y presente de los manuales escolares», Educación y pedagogía 13, no. 2930 (2001): 210 .
} 
escolares también son depositarios de emociones y sentimientos, ${ }^{26}$ sobre todo cuando se trata de periodos históricos o contenidos tan convulsos y trágicos como el aquí referido.

Por tanto, el presente estudio parte del análisis del trasfondo ideológico y cultural del fascismo en Italia. La principal técnica desarrollada para el estudio de los textos escolares es el análisis de contenido. Basado en la creación de un sistema de categorías, se toman como referencia las experiencias de trabajos realizados con manuales de materias y/o periodos similares, como los llevados a cabo por Emilio Castillejo Cambra, Joaquín García Puchol y Teresa Rabazas Romero en España y Anna Ascenzi, Dorena Caroli o Roberto Sani en Italia. ${ }^{27}$ De forma complementaria se contempla el análisis de las ilustraciones de los textos escolares y su diálogo con el texto.

Para ello, se ha dispuesto de una categoría de análisis -o hilo conductor - centrado en la representación del enemigo, tanto a nivel textual como gráfico, de todos los textos redactados por la editorial nacional italiana la Libreria dello Stato. Este criterio responde a la política del texto único implantada en la dictadura de Mussolini desde el curso 1930$1931,{ }^{28}$ cuando se acaba con la diversidad de manuales escolares, teniendo como finalidad el imponer un único ejemplar en cada año de la etapa elemental, la cual estaba compuesta por cinco cursos entre los seis y

\footnotetext{
${ }^{26}$ Kira Mahamud Angulo y Ana $\mathrm{M}^{\mathrm{a}}$ Badanelli Rubio, «Los contextos de transmisión y recepción de los manuales escolares: una vía de perfeccionamiento metodológico en manualística», História da Educação 20, no.50 (2016): 29-48; Ana M ${ }^{\mathrm{a}}$ Badanelli Rubio y Kira Mahamud Angulo, «Entre la ruptura y la continuidad de esquemas socioemocionales en los libros de lectura de la escuela primaria en el tardofranquismo (1959-1975)», Historia y Memoria de la Educación 2 (2015): 125-160.

${ }^{27}$ Emilio Castillejo Cambra, Mito, legitimación y violencia simbólica; Joaquín García Puchol, Los textos escolares de historia en la enseñanza española (1808-1900) (Barcelona: Universidad de Barcelona, 1993); Teresa Rabazas Romero, Los manuales de pedagogía y la formación del profesorado en las escuelas normales de España (1839-1901) (Madrid: UNED, 2001); Anna Ascenzi y Roberto Sani, Il libro per la scuola tra idealismo e fascismo. L'opera della Commissione centrale per l'esame dei libri di testo da Giuseppe Lombardo Radice ad Alessandro Melchiori (1923-1930) (Milán: Vita e Pensiero, 2005); Dorena Caroli, «L'insegnamento della storia antica e medioevale nelle scuole fasciste e sovietiche fra le due guerre mondiali: manuali di scuola elementare a confronto", Historia y Memoria de la Educación 2 (2015): 321-352; Roberto Sani, Education, school and cultural processes in contemporary Italy (Macerata: Edizioni Università di Macerata, 2018).

28 Anna Ascenzi, Metamorfosi della cittadinanza. Studi e ricerche su insegnamento della storia, educazione civile e identità nazionale in Italia tra Otto e Novecento (Macerata: Edizioni Università di Macerata, 2009), 239.
} 
once años. Estos ejemplares compilaban en su interior contenidos de diversas materias, convenientemente divididas dentro de estos.

En esta línea, y como señala la profesora Anna Ascenzi, el año 1934 supondría asimismo en la política del libro de texto italiano un cambio paradigmático. A partir de este momento, sobre todo en la materia de historia, en el régimen de Mussolini «la formación ideológica de las nuevas generaciones en el ámbito de la identidad nacional y del sentimiento patriótico convergían en la construcción integral del fascista, introduciendo una identificación entre la pertenencia nacional y la adhesión a los principios del régimen». ${ }^{29}$ Resulta conveniente señalar que este replanteamiento en la política educativa del régimen italiano encaja con el planteamiento expuesto por Eden McLean, quien en el contexto de estos años expone el interés de la dictadura italiana por conformar una identidad nacional italiana a través de otro giro en su planteamiento identitario, pasando de la evocación al pasado imperial romano a exaltar su inmortalidad. ${ }^{30}$ Este hecho redundará en los textos escolares, buscando una identidad que en algunos casos traspase las fronteras nacionales de la Italia fascista, y que asimismo redefina la demarcación espaciotemporal del otro. Y lo hará también en lo referente a la Guerra Civil Española.

Los currículos de 1934, promulgados por el ministro de instrucción pública Francesco Ercole, dan una idea de la importancia que dio el régimen fascista a la escuela para promulgar su ideario. En este sentido, el más explícito es el de historia. En el de la tercera clase elemental debían estudiarse a los héroes de la historia de Italia, desde 1848 hasta la fecha, así como lecturas de proclamas, cartas y recuerdos de los principales líderes y mártires nacionales. En el quinto curso, también dedicado a la historia contemporánea, aparece explícitamente la historia del Resurgimiento, desde la Gran Guerra hasta la revolución fascista, a través de lecturas sobre las figuras y episodios más gloriosos de acción colectiva e individual, así como las grandes obras públicas del fascismo y las fuerzas armadas. Algo parecido ocurre en la materia de Geografía. En ella, en la cuarta clase se explicitan que el alumnado deberá aprender la geografía física y política nacional, donde aparecen aspectos etnográficos,

\footnotetext{
29 Anna Ascenzi, Metamorfosi della cittadinanza, 241.

${ }^{30}$ Eden K. McLean, Mussolini's Children: Race and Elementary Education in Fascist Italy (Lincoln-Londres: Nebraska University Press, 2018).
} 
artísticos y culturales, así como el estudio de las colonias italianas. Especial interés merece el temario dedicado a la quinta y última clase de la enseñanza elemental, donde se hace referencia a la geografía europea, y se dedica un apartado a los italianos en el extranjero. ${ }^{31}$ Sin embargo, en los currículum de lectura no aparece explicitado que los tipos de texto que debiera leer el alumnado tuviera una temática determinada, ${ }^{32}$ si bien como se comprobará posteriormente, sí serán un vehículo para la transmisión de los principios del fascismo.

Por tanto, para realizar el análisis del conflicto bélico español, la visión del enemigo y de la intervención italiana se han seleccionado los textos de las materias de lecturas, historia, geografía y enseñanzas patrióticas, ${ }^{33}$ por ser aquellas en las cuales el contenido político tenía mayor cabida o presencia, como se ha podido observar en los currículos. Los ejemplares fueron consultados en el Centro di ricerca sulla storia del libro scolastico e della letteratura per l'infanzia - Museo di Storia della Scuola "Paolo e Ornella Ricca» de la Università degli Studi di Macerata (Italia), entre los años 2018 y 2019, constando de una muestra inicial de veintisiete textos escolares entre los años seleccionados.

\section{LA GUERRA CIVIL ESPAÑOLA EN LOS TEXTOS ESCOLARES ITALIANOS DE LA ESCUELA ELEMENTAL}

De acuerdo con los textos escolares seleccionados, la aparición de la Guerra Civil en los manuales italianos data del año 1938, y la última aparición se da en el año 1942. Ambas fechas resultan significativas. La primera, porque si bien la Guerra Civil dio comienzo en el año 1936 y la intervención italiana comenzó en ese mismo año, ${ }^{34}$ el hecho de que en menos de dos años se editen manuales escolares que incluyan este acontecimiento explica la importancia que dio el gobierno italiano a promocionar su ayuda al bando aliado de Franco con la finalidad de salvar a

\footnotetext{
${ }_{31}$ Enzo Catarsi, Storia dei programmi della scuola elementare (1860-1985) (Florencia: La Nuova Italia, 1990).

32 Enzo Catarsi, Storia dei programmi.

${ }_{33}$ En el caso de las enseñanzas patrióticas se consulta el texto Il primo e secondo libro del fascista, editado por el Partido Nacional Fascista italiano. En los programas de la escuela elemental no aparece en sí mismo un apartado dedicado a esta materia.
}

34 Álvaro Lozano, Mussolini y el fascismo italiano... 
España del caos, aun cuando la contienda no había llegado a su fin. Fue por tanto en este punto cuando se dio mayor presencia de la ayuda del Duce a su aliado español en los textos escolares. Por otro lado, Mussolini dejó de ser presidente del consejo de ministros de Italia en 1943, momento en el que Italia, y el Eje, se encontraban en una situación de debilidad, a la cual se añadió el comienzo de la invasión británica y estadounidense. ${ }^{35}$

El primer caso, como se ha señalado, data del año 1938 en un texto de lecturas. Se trata del libro L'aratro e la spada. Letture per la III clase dei centri rurali ( El arado y la espada. Lecturas para la tercera clase elemental de los centros rurales»), y fue escrito por Alfredo Petrucci. Considerado como uno de los principales poetas y autores de textos escolares del fascismo italiano, Petrucci contó con una prolífica literatura escolar donde destacan obras como L'italiano nuovo («El italiano nuevo») o la aquí analizada. ${ }^{36}$ En esta, se incluye un apartado dedicado a los cuentos para dormir, I racconti della sera ( Los cuentos de la noche»), donde uno de ellos, titulado Le campane di Malaga («Las campanas de Málaga»), narra la historia de un joven soldado italiano, Stefano Berta, establecido en la ciudad andaluza desde hace doce años, y donde conoció a su esposa, también italiana, con la que tuvo un hijo, Dreuccio. Rápidamente la historia se inserta en el marco de la Guerra Civil, con un arranque verdaderamente trágico para los lectores: la madre de Dreuccio había sido asesinada por los militares rojos al poco de comenzar la guerra mientras rezaba en una iglesia, como se puede observar en el siguiente fragmento de la historia:

Pero entonces estalló la guerra civil; [...] [Stefano Berta] se había alistado en las filas nacionales, y su madre [de Dreuccio], sorprendida por los milicianos rojos mientras estaba en la iglesia rezando con otras mujeres, fue asesinada brutalmente. A Dreucio le pareció que estaba solo en el mundo: su padre no daba noticias y su abuela, aplastada por el dolor, estaba ausente. Se dedicó a trabajar en la tienda, y todos los italianos que la frecuentaban lo

\footnotetext{
35 Philip Morgan, The fall of Mussolini: Italy, the italians, and the Second World War (Oxford: Oxford University Press, 2007).

36 Edoardo Brandani, Giorgio DiGenova y Massimo Duranti, "L'uomo della Provvidenza". Iconografia del Duce (1923-1945) (Bolonia: Edizioni Bora, 1997), 34; Eden McLean, Mussolini's Children...
} 
amaban. Pero hubo dos hombres que cuando vinieron a pedir a tomar un café [...] lo miraban de reojo. Después se sentaron en una mesa con aire de superioridad y se quedaron para observar quiénes entraban y quiénes salían. ${ }^{37}$

La historia, una vez muerta la madre, se focaliza en otro personaje femenino: la abuela. Aquellos hombres que frecuentaban la tienda de Dreuccio aparecen nuevamente en la historia y ponen en peligro la vida de la nonna, acompañándolo de imágenes que contribuían a profundizar en el miedo a los milicianos republicanos. Como se puede observar en la ilustración (imagen 1), el joven italiano se interpone para defender a su abuela, lo cual le pone en peligro. En la imagen se puede observar cómo eran hombres de gran constitución. Uno de ellos bebía y animaba al otro, que, colocado frente al joven italiano, se disponía a propinarle un golpe con una escopeta. Esta ilustración resulta destacable por la crueldad, victimización, y sobre todo, por la desproporción física de los varones respecto al niño.

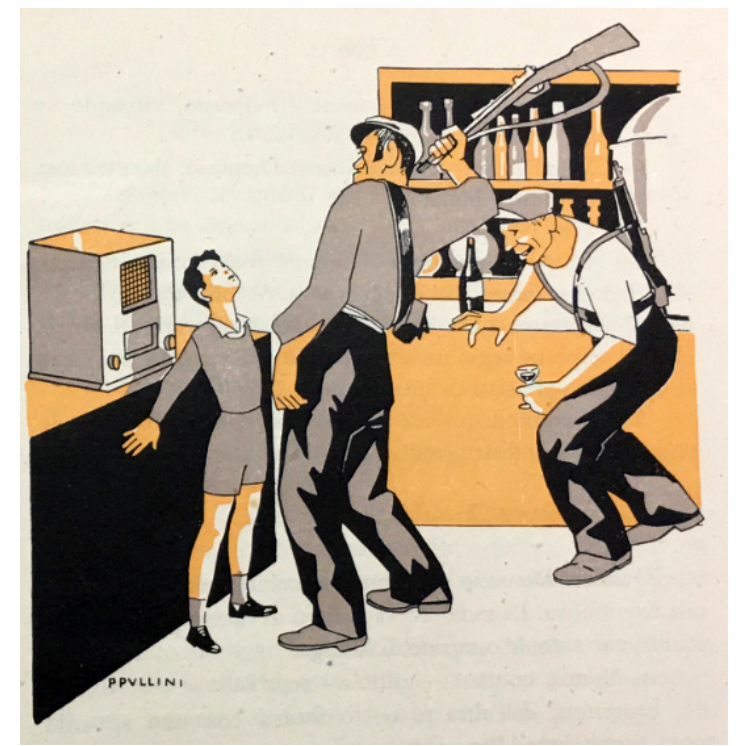

Imagen 1. Ilustración del cuento Le campane di Malaga. ${ }^{38}$

\footnotetext{
37 Traducido de: Alfredo Petrucci, «I racconti della sera. Le campane di Malaga», en L'aratro e la spada. Letture per la III clase dei centri rurali, ed. Alfredo Petrucci (Roma: La Libreria dello Stato, 1938), 196-200.

${ }^{38}$ Alfredo Petrucci, «I racconti della sera. Le campane di Malaga», 199.
} 
Durante la disputa, los rojos intentaron humillar a Dreuccio cuando supieron que era italiano, obligándole a decir abajo Italia. Sin embargo, el joven se rebeló diciendo justo lo contrario, lo que aumentó el enfado de los milicianos:

—Y bien, grita con nosotros: ¡Abajo Italia!

— ¡Viva Italia! — gritó Dreuccio con todo su aliento, mientras en la radio continuaba sonando:

Por el Duce, por el Imperio. ${ }^{39}$

Finalmente, los hombres salieron de allí, porque justo en aquel instante sonaron las campanas de la ciudad. En ese preciso momento, Málaga había quedado bajo el control del bando sublevado gracias a la intervención italiana.

El fragmento de la historia da cuenta de la dureza proyectada a las nuevas generaciones de niños y niñas instruidas en el fascismo italiano sobre lo ocurrido en España, utilizando la figura de un niño con el que empatizar y del miedo por la muerte de seres queridos, sobre todo en el caso de la madre. Asimismo, la aparición del personaje de la abuela potenciaba la carga emocional, impactando así a los pequeños lectores italianos. En definitiva, la concepción de la madre y la abuela, como personas bondadosas, vulnerables, y ante todo religiosas, añadido a la situación de riesgo propia de un conflicto bélico, contribuyen a generar una concepción de quien pone en peligro su integridad —en este caso el bando republicano-, demonizándolo.

Los libros de lectura fueron un espacio de propaganda ideal para el régimen fascista de Mussolini. La Guerra Civil Española vuelve a aparecer, nuevamente, en el texto de Letture per la quinta classe elementare dei centri urbani ( Lecturas para la quinta clase elemental de los centros urbanos»), escrito por Piero Bargellini en 1942. Bargellini fue una de las principales figuras en la literatura italiana durante el fascismo. Dentro de sus muchos perfiles destaca el plano educativo. El florentino fue maestro de enseñanza primaria desde 1920, de enseñanza intermedia entre 1929 y 1931, director entre 1931 y 1936 y finalmente inspector

\footnotetext{
39 Alfredo Petrucci, «I racconti della sera. Le campane di Malaga», 199.
} 
entre 1937 y 1948. Fue un admirador de Mussolini, al que dedicó enérgicos halagos en su obra Retrato virile («Retrato viril»), en una clara exaltación de la masculinidad con un claro conocimiento de los recursos literarios. Sobre su adhesión al régimen fascista, escribió sendas publicaciones mostrándose contrario al liberalismo europeo y al comunismo ruso. Sus principales aportaciones en prensa tuvieron lugar en revistas como Critica fascista o Primato. Precisamente, dentro del ámbito de las publicaciones participaría activamente en Il Frontespizio, de corte eminentemente católico, y donde Bargellini profesó un férreo antilaicisimo. ${ }^{40}$

En este manual escolar aparecen varios relatos vinculados a la Guerra di Spagna. El primero de ellos lleva por título Logroño, donde describe y reflexiona sobre la crudeza con la que tiene lugar una Guerra Civil, la peor de las posibles para el autor:

Entre todas las guerras, la civil es la más triste, la más amarga, la más atroz. Se divide y se arma uno contra el otro, los hombres de la misma nación, los ciudadanos de la misma ciudad, a menudo incluso la guerra interna.

De hecho, en la guerra de 1938 [sic], los propios españoles fueron los que destruyeron las ciudades españolas. Con las mismas manos destruyeron en la guerra lo que habían construido en paz. Los hijos de la blasfemia demolieron las hermosas iglesias erigidas por su padre creyente. El Pueblo arrojó los palacios de la nobleza, sin pensar que borró los signos de la civilización española y el arte en la tierra de España. ${ }^{41}$

En esta ocasión, el enemigo aparece como un blasfemo que atenta contra las iglesias, los edificios sagrados que a ojos del autor no deberían

\footnotetext{
${ }^{40}$ Istituto dell'Enciclopedia Italiana, Dizionario biografico degli italiani. Volume 34 (Roma: Istituto dell'Enciclopedia Italiana, 1980); Jorge Dagnino, Faith and fascism. Catholic intellectuals in Italy, 1925-43 (Londres: Palgrave Macmillan, 2017); Francesco Leoni, «El disenso católico en Italia durante el fascismo», Revista de Estudios Políticos 35 (1983), 235-255; Eden K. McLean, Mussolini's Children...; Barbara Spackman, Fascist Virilities. Rhetoric, Ideology, and Social Fantasy in Italy, (Minnesota: University of Minnesota Press, 2008).

${ }_{41}$ Traducido de: Piero Bargellini, «Logroño», en Letture per la quinta classe elementare dei centri urbani, ed. Piero Bargellini (Roma: La Libreria dello Stato, 1942), 118. Asimismo, resulta destacable que se hable erróneamente de la guerra de 1938, fecha que además coincide con la primera aparición del conflicto bélico en los textos italianos del fascismo.
} 
ultrajarse, así como los edificios de la aristocracia, vinculándolo a la idea del valor patrimonial. A lo largo de la historia, dividida en los capítulos titulados I legionari italiani («Los legionarios italianos»), Le feste natalizie («Las vacaciones de Navidad»), La Befana («La Epifanía») e Il suono della tromba («El sonido de la trompeta»), la visión del otro no resulta explícita, si bien se realizan descripciones de la situación en que ha quedado la ciudad de Logroño, resaltando la implicación del ejército italiano y el apego que la ciudad y sus gentes tuvieron a la división enviada por Mussolini. Se refleja una realidad devastadora, con dificultades para la alimentación y la pobreza generalizada, aunque siempre desde el protagonismo de la intervención italiana.

La finalización de la Guerra Civil se plasmó ampliamente en los textos escolares italianos. El encargado de su redacción fue Luigi Rinaldi, quien redactó el capítulo La guerra di Spagna è terminata en Il libro della quinta clase elementare. Letture («La guerra de España ha terminado» y «El libro de la quinta clase elemental. Lecturas», respectivamente), editado en los años 1939 y 1941, inmediatamente después de la finalización del conflicto bélico. Rinaldi fue otro de los autores más destacados en la literatura escolar del régimen fascista. Sus libros, pertenecientes a materias como la historia y las lecturas, destacaron por mensajes de marcado carácter ideológico y afín al Duce, una figura alabada a lo largo de sus textos. ${ }^{42}$

Quizá este texto, en el plano de las lecturas, sea el que mejor explicite la visión que se reflejó en los libros de texto sobre el enemigo común de Franco y Mussolini en España: el comunismo de Rusia.

A lo largo del texto son varias las referencias que aluden de forma directa a este otro:

El 28 de marzo de 1939 (Año XVII), doscientos mil soldados, pertenecientes a todos los cuerpos del ejército nacional y a las divisiones legionarias Littorio y Frecce Nere, entraron victoriosamente en Madrid, después de haber luchado de manera amarga y valerosa durante aproximadamente dos años y medio contra los comunistas pagados e incitados por Moscú. [...]

\footnotetext{
42 Mariella Collin, «Les libres de lecture italiens pour l'ècole primaire sous le fascisme (1923-1943)», Histoire de l'Éducation 127 (2010): 57-94.
} 
Rusia había incitado España con el fin de llevarla al nefasto bolchevismo, negador de la Fe, al odio hacia la sana energía, enemigo del orden y contrario a todos los pueblos rectos de gobiernos civiles. Depositado el odio en el corazón de innumerables desgraciados pertenecientes a las ínfimas clases de Francia, Inglaterra, Rusia y España, les había armado y mandado a combatir por el triunfo de la bandera roja. ${ }^{43}$

El enemigo estaba claramente definido como sujeto político, ideológico e incluso religioso. Queda descrito como un mal propagado en Occidente, en los principales países donde el fascismo no había triunfado -y donde tampoco lo había hecho con claridad el comunismo, a excepción de Rusia-. En cualquier caso, en el contexto español, Italia no había permitido que el comunismo ni las democracias europeas occidentales cruzaran los Pirineos.

A este respecto, se intercalan las intervenciones que el Duce tuvo sobre la intervención en España y su lucha anticomunista:

Los bolcheviques habían declarado pomposamente: «España será la tumba del fascismo». Mussolini, en su discurso de Génova, respondió: «Es infinitamente más probable que España sea la tumba del comunismo». Como siempre, Él tenía razón. ${ }^{44}$

Resulta destacable la incorporación en los textos escolares de fragmentos de los discursos del dictador, con una proyección de este como si se tratara de un dios o emperador. Por último, el texto finaliza con un giro narrativo, dirigiéndose directamente a los niños y niñas que leyeran aquellas páginas, advirtiéndoles sobre la contundencia del régimen italiano:

No es posible narraros a vosotros, niños y niñas de Italia, la infamia e ignominia de la cual los bolcheviques quedaron manchados durante la guerra civil española. Robaron, saquearon, destruyeron, quemaron y mataron sin piedad, sin tener en cuenta ni siquiera a las iglesias. Pero finalmente se erradicaron las

\footnotetext{
${ }_{43}$ Traducido de: Luigi Rinaldi, «La guerra di Spagna è terminata», en Il libro della quinta clase elementare. Letture, ed. Luigi Rinaldi (Roma: La Libreria dello Stato, 1939), 156.

${ }^{44}$ Luigi Rinaldi, «La guerra di Spagna è terminata», 157.
} 
fuerzas oscuras de la tiranía y se escuchó a uno de los cabecillas bolcheviques más crueles, el general Miaja, exclamando: «iTodo está terminado!».

Los enemigos de Italia y del fascismo terminaron fatalmente..$^{45}$

En definitiva, el texto de Rinaldi supone el ejemplo más clarificador del discurso construido en Italia sobre la visión del enemigo político en la guerra de España. Cabe destacar que la narración de este capítulo fue acompañada de una ilustración que evidenciaba parte de la simbología del que posteriormente adoptaría el Régimen franquista, la cual aparece acompañada con il fascio y unos banderines con la enseña italiana (imagen 2).

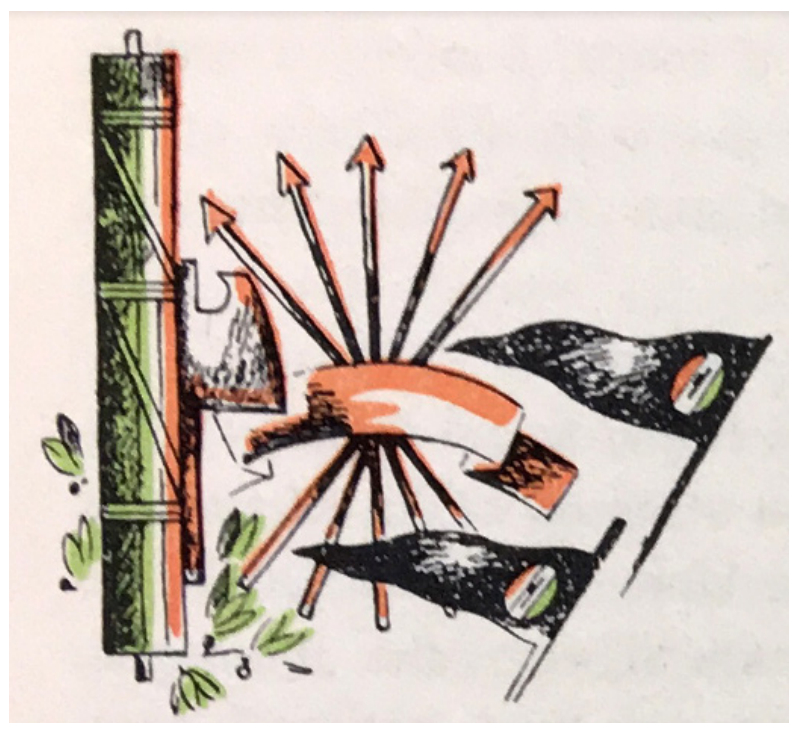

Imagen 2. Ilustración de la lectura La guerra di Spagna è terminata. ${ }^{46}$

Por otro lado, encontramos los textos de historia y geografía. En las ediciones de 1940 y 1941, los textos de ambas asignaturas, respectivamente, recogen las hazañas de los italianos en la guerra española. En el caso de historia, el capítulo dedicado a esta materia del libro Il libro della terza classe elementare. Religione, Grammatica, Storia, Geografia, Aritmetica («El libro de la tercera clase elemental. Religión, Gramática, Historia,

\footnotetext{
${ }^{45}$ Luigi Rinaldi, «La guerra di Spagna è terminata», 157.

${ }^{46}$ Luigi Rinaldi, «La guerra di Spagna è terminata», 156.
} 
Geografía, Aritmética»), fue redactado por Ezio Bonomi, un autor prolífico en la literatura escolar del fascismo. Encargado fundamentalmente del apartado de lecturas, destacó por esta obra y por el libro Celebrazioni patriottiche fasciste religiose ( Celebraciones patrióticas fascistas religiosas»), las cuales contenían mensajes de un explícito apoyo al régimen de Mussolini. Tras la Segunda Guerra Mundial, como apunta Piergovani Genovesi, en el Elenco dei libri di testo per le scuole elementari («Elenco de libros de texto para la escuela elemental») de 1945, su estrecha y explícita vinculación con el fascismo a través de sus obras escolares hizo que junto al nombre de Ezio Bonomi apareciera una anotación que remarcaba las reservas sobre él. ${ }^{47}$

En este libro de la tercera clase elemental, se incluye un apartado titulado I legionari italiani e la Guerra di Spagna ( Los legionarios italianos y la Guerra de España»), que recoge la finalización del conflicto y la aportación de la Italia fascista a su consecución, y donde nuevamente se vuelve a recoger la idea del comunismo como enemigo común:

Tan pronto como terminó la guerra por la conquista del Imperio, se abrió un nuevo campo de batalla para los valientes legionarios italianos.

España estaba comprometida en una heroica guerra de independencia contra la intrusión comunista. Voluntarios italianos se apresuraron en el auto de los maravillosos soldados del Generalísimo Franco: y en la tierra y en el cielo de España se reafirmaron las brillantes virtudes de los guerreros del pueblo italiano.

Málaga, Guadalajara, Santander, Bilbao, Tortosa, Barcelona y Madrid fueron las etapas de la guerra victoriosa, consagradas por la sangre de mil y un héroes españoles e italianos.

La tierra comunista en España seguirá siendo una página de vergüenza en la historia de la vieja Europa. ${ }^{48}$

\footnotetext{
${ }_{47}$ Piergiovani Genovesi, Il manuale di storia in Italia. Dal fascismo alla Repubblica, (Milano: FrancoAngeli, 2009).

48 Traducido de: Ezio Bonomi, «I legionari italiani e la guerra di Spagna», en Il libro della terza classe elementare. Religione, Grammatica, Storia, Geografia, Aritmetica, ed. Ezio Bonomi (Roma: La Libreria dello Stato, 1940), 125-126.
} 
La retórica victoriosa del régimen italiano se mezcló con la humillación hacia el bando republicano, cuyo espacio tilda como uno de los más humillantes de la historia del continente europeo.

En cuanto a la geografía, en 1941 se publicó una nueva edición de Il libro della quinta classe elementare. Aritmetica, Geografia, Scienze ( $\mathrm{El}$ libro de la quinta clase elemental. Aritmética, Geografía, Ciencias»), a cargo de Carmelo Cottone, un maestro, director e inspector escolar sardo. En 1938 se dirige a Roma, entrando en 1942 a la Dirección General de Educación Primaria, bajo el ministerio de Giuseppe Bottai. ${ }^{49}$ En el apartado de geografía de este manual, el autor hace un repaso por los principales países de Europa. En el caso de España se incluye una breve reseña histórica sobre la Guerra Civil, donde se afirma:

Recientemente, con la ayuda de los legionarios italianos, España se ha liberado del desorden, para volver a la civilización católica y latina.

Indudablemente, la guerra civil ha dejado trágicas ruinas, tanto por la enorme cantidad de víctimas como por la destrucción de la guerra.

El Caudillo ha enumerado más de 70 mil asesinatos solo en Madrid, 20 mil en Valencia, 54 mil en Barcelona. No menos de un millón son las víctimas españolas de la guerra. Devastó las ciudades más pobladas, incendió cientos de aldeas, abandonó y destruyó miles de hogares, las fuentes de riqueza empobrecidas.

España tendrá que superar enormes dificultades para la redención. Las ruinas que dejó la guerra son enormes y se necesitará un gran esfuerzo para repararlas. La reconstrucción de España requiere voluntad deliberada y energía incansable.

Debemos tener fe en la resurrección de España. Un pueblo que, después de siglos de decadencia y abandono, socavó durante más de cinco años en todos sus núcleos vitales. Sin embargo, encuentra la fuerza para levantarse en armas, apresurarse a ofrecerse voluntariamente bajo las banderas de Franco y, aunque con la

\footnotetext{
${ }^{49}$ Renato Andreolo et al., Educazione moderna e scuola di base. Studi in onore di Carmelo Cottone (Brescia: La Scuola, 1973); Piergiovani Genovesi, Il manuale di storia in Italia...
} 
ayuda de naciones amigas, lidera una guerra sangrienta y victoriosa durante tres años, siendo digno de vivir y ganar en la carrera de naciones civilizadas..$^{50}$

A través del fragmento de Cottone se hace un balance cuantitativo de las bajas producidas en la guerra y del devastador resultado de la misma para la recuperación de todos los pueblos y ciudades españolas, siempre desde la visión del bando sublevado. En la lectura sobrevuela el desorden y el caos originados por los republicanos, y se enfatiza en la cuestión étnica de la civilización, nuevamente católica, pero también latina. Este punto de encuentro enlaza con la idea de Mussolini de hacer resurgir un imperio mediterráneo en el que España y el régimen de Franco sería un aliado indispensable pese al complicado futuro que esperó al Duce pocos años después. ${ }^{51}$

Finalmente, se encuentra el texto bíblico del fascismo italiano: Il primo e secondo libro del fascista ("El primer y segundo libro del fascista»), editado por el Partido Nacional Fascista de Italia. En él se declaran los principios del partido y del fascismo, las reseñas a los principales personajes afines al régimen, y, por último, un breve calendario con los hitos más relevantes. En el periodo comprendido por la Guerra Civil Española se recogen dos hechos significativos para los fascistas italianos:

1936-38. Los Camisas Negras italianos acuden a España a combatir contra el bolchevismo y reafirman fúlgidamente la tradición militar italiana, cubriéndose de gloria en las batallas de Málaga, Santander, Bilbao, Tortosa, Albentosa, Barracas.

[...]

13 de febrero de 1941 (Año XIX)

Encuentro entre el Duce y el Caudillo en Bordighera. ${ }^{52}$

\footnotetext{
${ }_{50}$ Traducido de: Carmelo Cottone, «Spagna», en Il libro della quinta classe elementare. Aritmetica, Geografia, Scienze, ed. Carmelo Cottone (Roma: La Libreria dello Stato, 1941), 162.

51 Álvaro Lozano, Mussolini y el fascismo italiano.

52 Traducido de: Partito Nazionale Fascista, Il primo e secondo libro del fascista (Roma: Partito Nazionale Fascista, 1942), 12, 14.
} 
Para el partido oficial del régimen fascista, el conflicto español y la posterior reunión entre ambos dictadores fueron acontecimientos reseñables en la adaptación de su diario a las escuelas.

En resumen, podemos afirmar que la Guerra Civil Española contó con una nutrida representación en los textos escolares del Régimen fascista italiano en las materias aquí analizadas. En ellos hubo un claro enemigo político, Rusia, si bien en el contexto aquí abarcado los textos de lectura se han mostrado más partidarios de reflejar la definición de un enemigo social. Estos eran hombres - pues fundamentalmente aparecen representados como militares-insensibles, profundamente anticatólicos, y, por ende, carentes de fe. Hombres despreciables y sin sensibilidad, por su actitud contra los personajes entonces más vulnerables: las mujeres y los niños. Hombres que ocasionaron el desorden y el caos que condujeron a España a la desgracia.

La caída del fascismo en Italia trajo consigo un profundo replanteamiento del contenido de los textos escolares, acompañado de una política revisionista con el pasado inmediato de la historia nacional, la cual no podía continuar haciendo apología de la ideología fascista, ni de los conflictos bélicos recientes en los que Italia había tomado parte como defensora de aquellos ideales. La Guerra di Spagna desapareció de forma radical de los textos, bien por un cambio curricular en la edición de los nuevos textos, o por omisión. La Italia posterior al Régimen de Mussolini se encontró en una grave y delicada situación económica que diezmó las posibilidades de las familias. Ante la imposibilidad de poder adquirir nuevos textos escolares para sus hijos e hijas, la realidad terminó imponiéndose y se continuaron utilizando libros editados durante la época de Mussolini, si bien capítulos como los referidos al conflicto español fueron arrancados literalmente de sus páginas. Los índices de estos textos quedaron como testigos de títulos como Frecce Nere (Camisas negras), La corona di Albania a Vittorio Emmanuele III (La corona de Albania a Victor Manuel III), Italia romana e fascista (Italia romana y fascista) o La guerra civile di Spagna è terminata (La guerra civil de España ha terminado), que fueron los últimos vestigios del fascismo en los libros de texto de las nuevas generaciones de italianos e italianas instruidas ya al albor de una época marcada por la necesidad del pacifismo y de la construcción de la memoria histórica. 


\section{CONCLUSIONES}

Los textos escolares contribuyen a la construcción de una identidad nacional propia, pero también ayudan a dibujar la identidad del enemigo. Como han mostrado los textos aquí utilizados, la identidad del otro puede no resultar tan explícita o evidente aparentemente, pero en cualquier caso sigue una línea que permite obtener una visión panorámica de todo aquello que generó rechazo y contra lo que se luchó en la Guerra Civil Española desde el bando sublevado. Los textos escolares de la última época del fascismo italiano coincidieron con la idea del enemigo que también proyectaron los textos escolares españoles de la época, en clara sintonía entre el discurso fascista y el franquista. El enemigo era rojo, comunista, bolchevique, y vinculado a Rusia. Asimismo, aparecía representado de forma generalizada como varón, pues estaba asociado al ejército. Este acababa con la vida de mujeres y niños, generalmente italianos, acercando así la realidad a los lectores del país transalpino, y haciendo hincapié en la crudeza e injusticia de los crímenes cometidos por el bando republicano en la contienda civil.

Dentro de los textos, los que han mostrado una mayor representación de este conflicto han sido los de lecturas. Este hecho puede deberse, en parte, a la posibilidad que ofrecen estas para la creación de relatos e historias ficticias ambientadas en contextos históricos reales. Sin embargo, el contenido de estos textos muestra hechos sobrecogedores a los niños y niñas de la escuela elemental italiana, generando un sentimiento de miedo y demonizando a un bando del conflicto y, por ende, al proyecto político que representa.

En definitiva, tanto la identidad como la alteridad se han mostrado como conceptos transnacionales, capaces de cruzar fronteras e internacionalizarse. En este caso, la concepción y representación del enemigo en el caso italiano se corresponde con la idea del otro impregnada por el bando sublevado o franquista. Franco y Mussolini proyectaron así en sus textos una visión del enemigo, si bien el dictador italiano centró el relato bélico directamente contra personajes italianos, para así causar una mayor impresión y rechazo entre las nuevas generaciones educadas en los últimos años del fascismo. 


\section{Nota sobre el autor}

CARlos SAnz Simón es graduado en Pedagogía (2015) y Máster en Investigación en Educación (2016) por la Universidad Complutense de Madrid. En esta institución actualmente cursa los estudios de Doctorado en Educación como contratado predoctoral en el Departamento de Estudios Educativos. Forma parte del grupo de investigación consolidado Claves históricas y comparadas de la Educación. Género e identidades (CLAVES, UCM) y pertenece al consejo editorial de la revista Cabás. Además, es miembro de la Sociedad Española de Historia de la Educación (SEDHE) y de la Sociedad Española para el Estudio del Patrimonio Histórico-Educativo (SEPHE). Actualmente desarrolla su tesis doctoral sobre la construcción de la identidad nacional en las escuelas primarias de España e Italia entre 1os años treinta y cincuenta del siglo XX. Sus principales líneas de investigación se centran en el estudio del nacionalismo en la escuela, la simbología patriótica, los textos escolares y las memorias de prácticas.

\section{REFERENCIAS}

Andreolo, Renato et al. Educazione moderna e scuola di base. Studi in onore di Carmelo Cottone. Brescia: La Scuola, 1973.

Ascenzi, Anna. Metamorfosi della cittadinanza. Studi e ricerche su insegnamento della storia, educazione civile e identità nazionale in Italia tra Otto e Novecento. Macerata: Edizioni Università di Macerata, 2009.

Ascenzi, Anna y Roberto Sani. Il libro per la scuola tra idealismo e fascismo. L'opera della Commissione centrale per l'esame dei libri di testo da Giuseppe Lombardo Radice ad Alessandro Melchiori (1923-1930). Milán: Vita e Pensiero, 2005.

Badanelli Rubio, Ana $\mathrm{M}^{\mathrm{a}}$ y Kira Mahamud Angulo. «Entre la ruptura y la continuidad de esquemas socioemocionales en los libros de lectura de la escuela primaria en el tardofranquismo (1959-1975)». Historia y Memoria de la Educación 2 (2015): 125-160. https://doi.org/10.5944/hme.2.2015.14366

Bargellini, Piero (Ed.). Letture per la quinta classe elementare dei centri urbani. Roma: La Libreria dello Stato, 1942.

Bel Martínez, Juan Carlos y Juan Carlos Colomer Rubio. «Guerra Civil y franquismo en los libros de texto actuales de Educación Primaria: análisis de contenido y orientación didáctica en el marco de la LOMCE». Cabás 17 (2017): 1-17.

Bonomi, Ezio. "I legionari italiani e la guerra di Spagna». En Il libro della terza classe elementare. Religione, Grammatica, Storia, Geografia, Aritmetica, editado por Ezio Bonomi, 125-126. Roma: La Libreria dello Stato, 1940. 
Boyd, Carolyn P. Historia patria. Politica, historia e identidad nacional en España: 1875-1975. Barcelona: Pomares Corredor, 2000.

Brandani, Edoardo, Giorgio DiGenova y Massimo Duranti. "L'uomo della Provvidenza”. Iconografia del Duce (1923-1945). Bolonia: Edizioni Bora, 1997.

Caroli, Dorena. "L'insegnamento della storia antica e medioevale nelle scuole fasciste e sovietiche fra le due guerre mondiali: manuali di scuola elementare a confronto». Historia y Memoria de la Educación 2 (2015): 321-352. https://doi.org/10.5944/hme.2.2015.13821

Casanova Ruiz, Julián. República y guerra civil. Volumen 8. Barcelona: Crítica - Marcial Pons, 2007.

Castillejo Cambra, Emilio. Mito, legitimación y violencia simbólica en los manuales escolares de Historia del franquismo. Madrid: UNED, 2008.

Catarsi, Enzo. Storia dei programmi della scuola elementare (1860-1985). Florencia: La Nuova Italia, 1990.

Choppin, Alain. «Pasado y presente de los manuales escolares». Educación y pedagogía 13, no. 29-30 (2001): 209-229.

Collin, Mariella. «Les libres de lecture italiens pour l'ècole primaire sous le fascisme (1923-1943)». Histoire de l'Éducation 127 (2010): 57-94.

Colomer Rubio, Juan Carlos. «La Guerra Civil y el Franquismo en libros de texto actuales de $6 .^{\circ}$ de primaria: una aproximación crítica». En Pensar con la historia desde el siglo XXI: actas del XII Congreso de la Asociación de Historia Contemporánea, coordinado por Pilar Folguera et al., 5175-5185. Madrid: Universidad Autónoma de Madrid, 2015.

Cottone, Carmelo. «Spagna». En Il libro della quinta classe elementare. Aritmetica, Geografia, Scienze, editado por Carmelo Cottone, 159-164. Roma: La Libreria dello Stato, 1941.

Dagnino, Jorge. Faith and fascism. Catholic intellectuals in Italy, 1925-43. Londres: Palgrave Macmillan, 2017.

Domínguez Méndez, Rubén. «La fascistización de las escuelas italianas en el extranjero. El caso de Barcelona (1922-1929)». Historia de la Educación. Revista interuniversitaria 33 (2014): 231-253.

García Puchol, Joaquín. Los textos escolares de historia en la enseñanza española (1808-1900). Barcelona: Universidad de Barcelona, 1993.

Genovesi, Piergiovani. Il manuale di storia in Italia. Dal fascismo alla Repubblica. Milano: FrancoAngeli, 2009.

Heiberg, Morten. Emperadores del Mediterráneo. Franco, Mussolini y la guerra civil española. Barcelona: Crítica, 2003.

Istituto della Enciclopedia Italiana. Dizionario biografico degli italiani. Volume 34. Roma: Istituto della Enciclopedia Italiana, 1980.

Leoni, Francesco. "El disenso católico en Italia durante el fascismo». Revista de Estudios Políticos 35 (1983): 235-255. 
Lozano, Álvaro. Mussolini y el fascismo italiano. Madrid: Marcial Pons Historia, 2012.

Mahamud Angulo, Kira y Ana M ${ }^{\mathrm{a}}$ Badanelli Rubio. «Los contextos de transmisión y recepción de los manuales escolares: una vía de perfeccionamiento metodológico en manualística». História da Educação 20, no. 50, (2016): 29-48. http://dx.doi.org/10.1590/2236-3459/62455

Marina Carranza, Marcos. «¿Qué guerra civil nos han explicado? La guerra civil en los libros de texto». En Historia, identidad y alteridad. Actas del III Congreso Interdisciplinar de Jóvenes Historiadores, coordinado por José Manuel Aldea Celada et al., 713-731. Salamanca: Hergar Ediciones, 2012.

McLean, Eden K. Mussolini's Children. Race and Elementary Education in Fascist Italy. Lincoln-Londres: Nebraska University Press, 2018.

Meda, Juri y Ana $\mathrm{M}^{\mathrm{a}}$ Badanelli Rubio. La historia de la cultura escolar en Italia y en España: Balance y perspectivas. Macerata: Edizioni dell'Università di Macerata, 2013.

Meda, Juri. «Invisible schools'. The public image of rural schools in Southern Italy in photographic inquiries and photo-reportages (1925-55)». Historia y Memoria de la Educación 8 (2018): 347-396. https://doi.org/10.5944/ hme.8.2018.19204

Montecchi, Luca. "La escuela primaria rural en Italia entre los siglos XIX y XX». Historia y Memoria de la Educación 7 (2018): 81-106. https://doi. org/10.5944/hme.7.2018.18747

Morandini, María Cristina. «I quaderni di epoca fascista veicolo di propaganda ideologica e strumento didattico: il fondo della scuola elementare Parini di Torino (1938-1942)». Historia y Memoria de la Educación 10 (2019): 383408. https://doi.org/10.5944/hme.10.2019.23365

Morente Valero, Francisco. «Los fascismos europeos y la política educativa del franquismo». Historia de la Educación. Revista interuniversitaria 24 (2005): 179-204.

Morgan, Philip. The fall of Mussolini: Italy, the italians, and the Second World War. Oxford: Oxford University Press, 2007.

Núñez Seixas, Xosé Manoel. «El miedo al extranjero, o el enemigo como invasor (1936-1939)». En Retóricas del miedo: imágenes de la guerra civil española, editado por Nancy Berthier y Vicente Sánchez-Biosca, 53-70. Madrid: Collection de la Casa de Velázquez, 2012.

Partito Nazionale Fascista. Il primo e secondo libro del fascista. Roma: Partito Nazionale Fascista, 1942.

Payne, Stanley George. Fascism in Spain, 1923-1977. Madison: University of Wisconsin Press, 1999.

Petrucci, Alfredo. L'aratro e la spada. Letture per la III clase dei centri rurali. Roma: La Libreria dello Stato, 1938. 
Pomante, Luigiaurelio y Roberto Sani. «The Gentile reform (1923) and academic strategies of the University of Macerata between national science and development of the local economy». Historia y Memoria de la Educación 3 (2016): 259-277. https://doi.org/10.5944/hme.3.2016.13875

Puelles Benítez, Manuel de. Política, legislación y educación. Madrid: UNED, 2017.

Rabazas Romero, Teresa. Los manuales de pedagogía y la formación del profesorado en las escuelas normales de España (1839-1901). Madrid: UNED, 2001.

Rinaldi, Luigi. "La guerra di Spagna è terminata». En Il libro della quinta clase elementare. Letture, editado por Luigi Rinaldi, 156-157. Roma: La Libreria dello Stato, 1939.

Roith, Christian. "Representaciones de la Guerra civil española en manuales de Historia del franquismo temprano». Historia de la Educación. Revista interuniversitaria 36 (2017): 321-342. http://dx.doi.org/10.14201/hedu201736321342

Sani, Roberto. Education, school and cultural processes in contemporary Italy. Macerata: Edizioni Università di Macerata, 2018.

Sanz Simón, Carlos y Teresa Rabazas Romero. «La identidad nacional en los manuales escolares durante la Segunda República Española». Bordón. Revista de Pedagogía 69, no. 2 (2017): 131-146. https://doi.org/10.13042/Bordon.2017.50578

Saz Campos, Ismael. Mussolini contra la II República. Hostilidad, conspiraciones, intervención (1931-1936). Valencia: Alfons el Magnànim, 1986.

Sevillano, Francisco. La cultura de guerra del "nuevo Estado» franquista. Madrid: Biblioteca Nueva, 2017.

Spackman, Barbara. Fascist Virilities. Rhetoric, Ideology, and Social Fantasy in Italy. Minnesota: University of Minnesota Press, 2008.

Valls Montes, Rafael. Historia y memoria escolar: Segunda República, Guerra Civil y dictadura franquista en las aulas (1938-2008). València: Universitat de València, 2009.

Vaquero Peláez, Dimas. Mussolini \& España, Franco \& Mussolini. Unas relaciones difíciles. Zaragoza: Comuniter, 2017.

Vaquero Peláez, Dimas. Credere, obbedire, combattere. Creer, obedecer, combatir... y morir. Fascistas italianos en la guerra civil española. Zaragoza: Mira Editores, 2007.

Venza, Claudio. «La Italia fascista en la tormenta española (1934-1939)». En Francone. La mirada de Mussolini en la guerra de España, editado por el Gobierno de Aragón, 31-40. Zaragoza: Gobierno de Aragón, 2009.

Viñas, Ángel. La República en guerra contra Franco, Hitler, Mussolini y la hostilidad británica. Barcelona: Crítica, 2012. 